\title{
Spatiotemporal Trends of Temperature Extremes in Bangladesh Under Changing Climate Using Multi- statistical Techniques
}

Javed Mallick

King Khalid University

Abu Reza Md. Towfiqul Islam ( $\nabla$ towfiq_dm@brur.ac.bd)

Begum Rokeya University https://orcid.org/0000-0001-5779-1382

Bonosri Ghose

Begum Rokeya University

H.M. Touhidul Islam

Begum Rokeya University

Yousuf Rana

Begum Rokeya University

Zhenghua Hu

Nanjing University of Information Science \& Technology

Shakeel Ahmed Bhat

4College of Agricultural Engineering and Technology, SKUAST- Kashmir

\section{Research Article}

Keywords: Extreme events, Global warming, Mutation analysis, detrended fluctuation analysis, climatic disaster

Posted Date: August 10th, 2021

DOl: https://doi.org/10.21203/rs.3.rs-662878/v1

License: (a) (1) This work is licensed under a Creative Commons Attribution 4.0 International License. Read Full License

Version of Record: A version of this preprint was published at Theoretical and Applied Climatology on October 26th, 2021. See the published version at https://doi.org/10.1007/s00704-021-03828-1. 


\title{
Spatiotemporal trends of temperature extremes in Bangladesh under
} changing climate using multi-statistical techniques

\author{
Javed Mallick ${ }^{1 *}$, Abu Reza Md. Towfiqul Islam², Bonosri Ghose ${ }^{2}$, H.M. Touhidul Islam², \\ Yousuf Rana ${ }^{2}$, Zhenghua $\mathrm{Hu}^{3}$, Shakeel Ahmed Bhat ${ }^{4}$ \\ ${ }^{1}$ Department of Civil Engineering, King Khalid University, Abha, Saudi Arabia
}

\begin{abstract}
The rise in the frequency and magnitude of extreme temperature phenomena across the globe has led to the recurrent incidence of global climate hazards, which have had severe effects on socioeconomic development. The daily maximum and minimum temperature datasets of 27 sites in Bangladesh were used to detect spatiotemporal trends of temperature extreme over Bangladesh during 1980-2017 based on ten temperature extreme indices using multistatistical modeling namely linear regression, Pearson correlation coefficient and factor analyses. Besides, mutation analyses based on the Mann-Kendall test, Sen's slope estimator
\end{abstract}


and Pettit test were employed to show the changing trend in extreme temperature. Results show that except for warmest days, the warm indices showed an increasing trend, mainly since the 2000s, while the growth rate was faster, and the response to global climate warming was sensitive. The cold indices demonstrated a reverse trend since the 2010s. Diurnal temperature range (DTR) and summer days (SU) increased faster, implying that the rising speed of daily max temperature was higher than of daily min-temperature in Bangladesh. The detrended fluctuation analysis (DFA) revealed a continuous increase in temperature extreme in the future except for cold days. The probability distribution functions (PDF) analysis revealed an evident variation of the curves in recent decades compared to the past three decades. Besides the warm night, DTR and SU primarily control the general warming trend of temperature extremes over Bangladesh during the study period. The mutation of the warm indices occurred before the cold index, indicating that the warm indices were more sensitive to global climate warming. The temperature extremes recognized in our research suggest that elevated warm temperature extremes due to global climate warming may have huge 41 implications on the sustainable development of Bangladesh in the forthcoming period.

42 Keywords: Extreme events, Global warming, Mutation analysis, detrended fluctuation analysis, climatic disaster. 


\section{Introduction}

45 Temperature extremes have critical effects on ecosystem imbalance, agricultural productivity, water resources and sustainable socioeconomic development (Easterling et al. 2000; Ciais et al. 2005;

47 Schmidli and Frei 2005; Benestad and Haugen 2007; Allen et al. 2010; Rammig and Mahecha, 2015;

48 Guo et al. 2019). Variations in temperature extremes in a warming climate have paid considerable 49 attention in recent years due to the enormous impact of severe temperature occurrences on society and ecosystems (Bandyopadhyay et al., 2012; Sun et al., 2014). Furthermore, the scientific community has emphasized measure to tackle the climate change impact on ecosystems and human livelihoods for 52 disaster prevention and mitigation (Smith 2011; Jiang et al. 2012; Endfield 2012; Garcia-Cueto et al. 2014; Sharma et al. 2018). As climate extreme events increased in many parts of the world, including Bangladesh (Hasan et al. 2013; Shahid et al. 2016; Mahmud et al. 2018; Khan et al. 2019). Thus, it is crucial to investigate spatiotemporal changes in Temperature Extremes for sustainable development over Bangladesh.

57 Extreme temperature phenomena are changing across the globe due to global warming (Alexander et al. 2006; Aguilar et al. 2005; Hidalgo-Muñoz et al. 2011; Coumou and Rahmstorf 2012; Abiodun et al. 2013; Coumou et al. 2013; Omondi et al. 2014). The fact is that global and local average temperatures are increasing, which have no bearing on the occurrence of extreme events (Finkel et al. 2018; Gleixner et al. 2020). However, severe temperatures may be more vital than mean temperatures for productivity and human survival, and local extreme temperature changes could significantly impact global mean temperature changes (Finkel et al., 2018; Gao et al., 2017; Katz et al., 1992). Several studies have 64 reported that the frequency of warm temperature indices is increasing, while the frequency of cold temperature indices is decreasing (Alexander et al. 2006; Tank et al. 2006; Piccarreta et al. 2015; Sheikh et al. 2015; Guan et al. 2015; Sun et al. 2016; You et al. 2017; Ullah et al. 2019). All these studies

67 looked at average temperature trends and temperature extremes, but the latter only looked at monthly 
68

69

70

71

72

73

74

75

76

77

78

79

80

81

82

83

84

85

86

87

88

89

and yearly maximum and minimum values as extremes. The Expert Team on Climate Change Detection and Indices (ETCCDI) has identified extreme temperature indices to illustrate better temperature extremes, commonly used in climate change-related studies in various parts of the world (Zhang et al., 2011). Therefore, a deep understanding of temperature extremes' trends and fluctuations is essential for developing accurate estimates of future climate change projections and answering scientific researchers', climate change analysts and decision-makers unique concerns.

Bangladesh is one of the world's top ten countries that could be severely affected by climatic extreme (Eckstein et al., 2017). The most immediate impacts of climatic extreme in Bangladesh, as elsewhere globally, are mainly due to increased daily temperatures and temperature-related extreme phenomena (Shahid et al., 2016). Temperature extremes have been observed in the country's agriculture (Sikder and Xiaoying, 2014) and other sectors (Shahid et al., 2016). Temperature variability is most likely to result in significant yield reductions in the agricultural industry in the future (Ghose et al., 2021). Plant development, pollination, and reproductive processes are all affected by higher temperatures (Tank et al., 2006; Sacks and Kucharik, 2011). A short period of unusually high or low temperatures can significantly negatively impact crop growth and yield (Mearns et al., 1984). Due to temperature extremes, total rice production in Bangladesh is expected to decline by 7.4\% per year from 2005 to 2050 (Sarker et al., 2012). Therefore, significant attempts should be made to estimate not only changes in mean temperature sequence but also changes in the frequency, magnitude, and duration of extreme temperature events (Easterling et al., 2000; Jones et al., 2001; Moberg and Jones, 2005; Alexander et al., 2006). However, the characteristics of climate extremes are poorly understood at the regional level. So, it is urgently needed to keep track of spatiotemporal variations in temperature extremes regularly at the regional level, including Bangladesh. 
In Bangladesh, many studies were performed to investigate the spatiotemporal variations of extreme climate indices (Hasan et al., 2013; Shahid et al., 2016; Mahmud et al., 2018). These studies reported that warm temperature events (cold temperature events) are rising (decreasing). However, the studies mentioned above are either concentrated on the two regions, and a limited number of meteorological stations (Mahmud et al. 2018), short time scales and a limited number of temperature indices (Khan et al., 2019), different data sources (Hasan et al., 2013). Besides, it is unclear whether and how those indices affect temperature extremes in Bangladesh both spatially and temporally. In addition to this, previous studies have not shown the long-term connection among extreme temperature indices using Detrended Fluctuation Analysis (DFA). To close the aforementioned research gaps, this study has four objectives:

1. To examine the spatiotemporal trends of temperature extremes from 1980 to 2017 in Bangladesh.

2. To identify the association among extreme temperature indices.

3. To predict long-term connection among ten temperature extremes indices.

4. To analyze the factor affecting the extreme temperature variation over Bangladesh.

The novel aspect of this research is that the trends and the associated connection of extreme temperature were analyzed in Bangladesh to understand their spatial and temporal variability. The findings will serve as a scientific foundation for future severe event prediction and hazard mitigation and prevention.

\section{Data and Method}

\subsection{Study Area Description}

Bangladesh is a sub-tropical country of South Asia situated in between latitude $20^{\circ} 34^{\prime} \mathrm{N}$ to $26^{\circ} 38^{\prime} \mathrm{N}$ and longitude $88^{\circ} 01^{\prime} \mathrm{E}$ to $92^{\circ} 41^{\prime} \mathrm{E}$ (Fig. 1) with complex hydro-geologic settings (Jerin et al., 2021; Ghose et al., 2021). Excluding some hilly area of Bangladesh, maximum portions of the land area in the floodplain (80\%) region (Rahman and Islam, 2019; Islam et al., 2021). In Bangladesh, the monthly 
113 average temperature ranges from $5.8^{\circ} \mathrm{C}$ (January) and $35.7^{\circ} \mathrm{C}$ (August), whereas the monthly average 114 precipitation varies between $1 \mathrm{~mm}$ (January) and $350 \mathrm{~mm}$ (July). The annual average temperature is $11526^{\circ} \mathrm{C}$, and the average yearly rainfall is about $2400 \mathrm{~mm}$ (Islam et al. 2020; Jerin et al., 2021). Seasonal 116 variations in rainfall are indistinguishable characteristics of its climate. The country's climate is 117 characterized by a hot and humid summer with heavy rain and a dry and mildly cold winter. Winter 118 (December to February), pre-monsoon (March to May), monsoon (June to September), and post119 monsoon (October to November) are the four predominant seasons of the country (Islam et al. 2021; 120 Salam et al. 2020). Bangladesh has an average daily mean relative humidity of $80 \%$ and a $3.72 \mathrm{~mm} / \mathrm{day}$ 121 evapotranspiration rate, respectively (Salam and Islam, 2020). The coldest month is January and the 122 hottest months in Bangladesh between April and October.

\section{$123 \quad 2.2$ Data source and quality control of the dataset}

124 Daily minimum and maximum temperature data are collected from Bangladesh Meteorological 125 Department (BMD). Though BMD has 43 weather stations across the country, 27 sites were selected for 126 this study because of the lack of availability of long-term temperature data. Thus, the daily Tmin and 127 Tmax data of 38 years from 1980 to 2017 were used in this study with missing values of less than $4 \%$. 128 The selected stations are uniformly scattered all over the country, which is assumed to be a perfect 129 representation for the whole country. Our study was analyzed variations in extreme temperature indices 130 based on daily minimum and maximum temperatures for 1980-2017. Many temperature series were 131 omitted from our analysis due to inhomogeneity. Missing data at each site were filling-up from the 132 records of nearby locations. In addition, the sites discarded due to the unavailability of data for a more 133 extended period was also used to fill up the missing values (Rahman et al. 2019). The BMD followed 134 the World Meteorological Organization (WMO) guidelines for weather data record and collection. 
135 Nevertheless, the quality control of the dataset is still imperative before investigating climatic extremes

136 because incorrect outliers influence the extremes significantly (Gao et al., 2015).

137 Quality control of site observation was initially done through systematic checking of data, namely, 138 positive records of climate variables; Tmin is lower than Tmax, and temperature less than $45^{\circ} \mathrm{C}$. The 139 time-series data were identified to be homogeneous and consistent at all locations (Hans, 1986). The 140 BMD staff also approved all data records through a data quality check. Serial autocorrelation is one of 141 the critical problems in trend analysis (Praveen et al., 2020). Assessment of serial autocorrelation in time 142 series for different lags showed correlation at $\mathrm{p}<0.05$, except for a few cases. Data were quality143 controlled by RClimDex1.1.

144 In this study, 10 extreme temperature indices were chosen from the indicators recommended by the 145 Expert Team for Climate Change Detection Monitoring and Indices (ETCCDMI). Recently, these 10 146 indices have been extensively adopted in extreme temperature study (Zhou et al., 2020; Islam et al., 147 2021). The indices were computed by using the RClimDex software package developed by ETCCDI 148 (http://cccma.seos.uvic.ca/ETCCDI). Table 1 presents a detailed description of these ten indices.

\subsection{Pettitt's Test}

Pettitt's test is a non-parametric test introduced by Pettitt (1979) applied to detect a change point in any

151 time series data with its significance test (Islam et al., 2020). In this study, Pettitt's test is used for 152 detecting change points among different extreme temperature indices. This test employed Mann153 Whitney statistic $U_{t}$, that examines if the two sets of sample $x_{1}, x_{2}, x_{3}, \ldots x_{t}$ and $x_{t+1}, x_{t+2}, x_{t+3} \ldots x_{n}$ are 154 from the similar population or not (Mu et al. 2007). The $\mathrm{U}_{\mathrm{t}}$ can be expressed as:

$$
U_{t}=\sum_{i=1}^{t} \sum_{j=t+1}^{n} \operatorname{sign}\left(x_{t}-x_{j}\right)
$$


$\operatorname{sign}\left(x_{t}-x_{j}\right)=\left[\begin{array}{cc}1, & \text { if }\left(x_{i}-x_{j}\right)>0 \\ 0, & \text { if }\left(x_{i}-x_{j}\right)=0 \\ -1, & \text { if }\left(x_{i}-x_{j}\right)<0\end{array}\right]$

155 The K (test statistic) and $\rho$ (confidence level) for the $n$ (sample length) are defined by Eq. (3-4):

$K=\operatorname{Max}\left|U_{t}\right|$

$\rho=\exp \left(\frac{-K}{n^{2}+n^{3}}\right)$

156 The null hypothesis is rejected if $\rho$ is lower than the specified significance level. The $\mathrm{p}$ (significance 157 probability) can be expressed as:

$p=1-\rho$

\subsection{Detrended Fluctuation Analysis (DFA)}

159 Detrended fluctuation analysis (DFA) is a novel method for assessing the long-term relationship in the 160 non-stationary time series data analysis, which is firstly presented by Peng et al. (1994) for the 161 investigation of DNA. The DFA method can prevent the wrong identification of artificial relationships 162 by eliminating local trends of the different time series (Rahman and Islam, 2019; Islam et al., 2021). 163 Nowadays, this method has been employed mainly to identify long-range associations among natural 164 systems following continuous improvement ( $\mathrm{Li}$ and Zhang, 2007). In this paper, DFA is used for 165 predicting upcoming trends in extreme temperature indices. The following procedure can calculate it:

166 For extreme climate series $\left\{x_{k}, k=1,2, \ldots N\right\}$, In which $\mathrm{N}$ represents the series length and $\mathrm{x}$ represents 167 mean. The cumulative deviation of the original series can be computed as:

$y(i)=\sum_{k=1}^{n}\left(x_{k}-\bar{x}\right)(i=1,2 \ldots \ldots \ldots)$

168 Then the latest series $y_{i}$ is ordered into Ns different sub-intervals through s length by Eq. (7):

$N_{s}=\operatorname{int}\left(\frac{N}{s}\right)$ 
169 For confirming the information as the series is not divisible, it is categorized again into inverse way. As 170 a result, a total of 2 Ns subintervals is created. Then Polynomial fitting is executed for each sub-interval $171 \mathrm{v}(\mathrm{v}=1,2, \ldots 2 \mathrm{Ns})$ data to achieve the trend function $y_{v(i)}$ in that series. The original series trend in sub172 function is filtered out by executing Eq. (8):

$y_{s(i)}=y(i)-y_{v(i)} i=(1,2, \ldots \ldots \ldots)$

173 wherein, $y_{v(i)}$ is second order polynomial though it can be first or higher order polynomial. To eliminate 174 the trend and computing of the each-interval variance is calculated by Eq. (9-10):

$$
\begin{aligned}
& F^{2}(v, s)=\frac{1}{s} \sum_{i=1}^{s}\left\{y[(v-1) s+i]-y_{v}(i)\right\}^{2} \quad\left(i=1,2, \ldots \ldots N_{s}\right) \\
& F^{2}(v, s)=\frac{1}{s} \sum_{i=1}^{s}\left\{y\left[N-\left(v-N_{s}\right) s+i\right]-y_{v}(i)\right\}^{2}\left(i=N_{s}+1, N_{s}+2, \ldots \ldots 2 N_{s}\right)
\end{aligned}
$$

175 The estimation of the second order wave function of the entire series by following Eq. (11):

$F(s)=\sqrt{\frac{1}{2 N_{s}} \sum_{v=1}^{2 N_{s}} F^{2}(v, s)}$

176 Power law relationship series of $\mathrm{F}(\mathrm{s})$ and $\mathrm{s}$ variations are computed by using Eq. (12):

$F(s) \sim s^{a}$ or $\ln F(s)=a \ln s+b$

177 The datasets are close fitted using least square method in dual logarithmic where 'a' (slope) of the trend 178 is scaled DFA index. The whole procedure is randomly divided and independent if there is $\mathrm{a}=0$ and $0<\mathrm{a}$ $179<0.5$ denotes the short-term relation with dependent process demonstrate that the time series data are 180 inversed to the prevailing trend. On the other hand, $0.5<\mathrm{a}<1$ indicates the continuous series and 181 approaching trend is same to the previous. When ' $a$ ' is nearby to 1 , the greater the change of similarity 182 and $\mathrm{a}=1$ denotes the procedure is $1 / \mathrm{f}$ sequence like a non-stationary casual cycle along with $1 / \mathrm{f}$ spectrum 
183 classified by scale invariance and a long-term relationship. Moreover, $\mathrm{a} \geq 1.5$ denotes the procedure is 184 brown-noise sequence.

\section{$185 \quad 2.5$ Trend analysis using multi-statistical techniques}

186 The nonparametric Mann-Kendall (MK) test is employed to detect a trend in extreme temperature

187 indices (Islam et al., 2019; Islam et al., 2021). It is renowned for its robustness in analysing non188 normally sequenced datasets and lower sensitivity to missing value (Islam et al., 2021). A trend free pre189 whitening (TFPW) method was employed to remove serial auto-correlation (Praveen et al. 2020; Jerin et 190 al., 2021). Correspondingly, Sen's slope (SS) estimator (Sen, 1968) was employed to determine the 191 frequency of change in extreme temperature indices. The elaborate process of the MK test and SS are 192 found in Islam et al. (2019) and Praveen et al. (2020).

193 Pearson's correlation coefficient was applied to reveal the relationship among extreme temperature 194 indices. The factor analysis was employed to detect extreme temperature factors across Bangladesh 195 (Rahman and Islam, 2019). The univariate linear regression analysis was used to identify the trend rate 196 of extreme temperatures indices in Bangladesh and each site (Donat et al., 2014). We Used the R studio 197 software to perform the M-K mutation test (Gallant and Karoly, 2010; Panda et al., 2014) and use the 198 student t-test to confirm the mutation change point and, increasing the credibility of the mutation 199 outcome.

200 3. Result

2013.1 Linear Regression Trends Analysis

202 The rate of the inter-decadal tendency of every single extreme temperatures index was quantified by 203 employing the linear regression technique, and its significance was examined (Figure 2). Based on the 204 time scale, the warm indices of extreme temperature demonstrated an increasing trend except for TXX 205 showed a decreasing trend during 1980-2015. The rate of the magnitude of DTR, SU, TXX, TNX, 
TX90p, and TN90p were 8.7e days/decades, 0.21 days/decades, 0.037 oC/decades, 0.01 oC/decades, 0.11 days/decades, and 0.12 days/decades, respectively (Figure 2), denoting that the warm indices of extreme temperature are rising significantly in Bangladesh. Among them, the rising rate of DTR and TNX were relatively shorter during the study period 1980 to 2015 . At the same time, the increasing rate of other indices was comparatively larger, mainly the rising rate of SU, which was the fastest, whose tendency of inter-decadal magnitude rate attained 0.21 days/decades (Figure 2b). As shown in Figure 2, except for TXX, the rest of the warm indices demonstrated an increasing trend from the 1990s to 2000, representing that there can be a warming occurrence in this period. DTR, SU and TX90 were changed smoothly before 2010, while abrupt upward change started since 2010 (Figure 2a, b, f). TN90 showed a comparatively short variation before the 1990s; after that, it had large fluctuations and showed an upward trend (Figure 2e). TNX exhibited changes that started after 1995; before 1995, the fluctuation was short (Figure 2h). The overall decreasing trend showed in TXX during the total study period, and two significant changes were in the 1990s and 2010s (Figure 2j). Based on the discussion mentioned above, the warm indices of extreme temperature exhibited an overall upward trend in the study period except for TXX in this research. Since 1995, the warm indices showed a rapid upward trend in line with tendency of global warming. Figure 2c shows that the TN10 significantly fluctuated before 2010, and significant fluctuation had started since 1985 (Figure 2d). In Figure 2g, the TNN had the most noticeable 
229 change and fluctuation from the 2000s, while the most significant fluctuation was after 2010. The 230 temporary fluctuation showed from 1980 to 1995 while the most considerable fluctuation and variation 231 exhibited after 1995 with decreasing trend in TXN (Figure 2f). By observing the above assessment, 232 TX10, TN10, TXN and TNN all exhibited a downward trend; notably, TX10, TN10 showed a rapid 233 decline speed.

\subsection{Long-Term Connection analysis Using DFA}

235 To explore the trend behaviours of fluctuation in forthcoming temperature extremes, a long-term 236 association assessment was conducted employing DFA, and the results are demonstrated in Figure 3a 237 j. The Figure 3 illustrates that the DFA ranging exponent in DTR, SU, TN10, TX10, TN90, TX90, TNN, 238 TNX, TXN, and TXX was $0.96,0.65,0.86,0.38,0.76,0.85,0.63,0.71,0.75$ and 0.86 respectively. In 239 the study period 1980 to 2015 , they all had a strong association, showing that the forthcoming 240 behaviours of trend in each single warm and cold temperature extremes are similar to the fluctuation 241 trend. Indeed, the warm temperature extremes will rise, and cold temperature extremes will decline in 242 the forthcoming period. The rate of change in the warm temperature indices (SU, TNX, and TN90) will 243 increase continuously than the other warm indices. The DFA values of these warm indices are not closer 244 to 1 . In cold temperature indices, TN10 will continue to decrease than the other cold temperature indices 245 except for TX10 due to its DFA value being larger than the other cold indices. We explored that the 246 sequence values of the DFA exponent of warm indices (SU, TNX, TN90) are less than the cold 247 temperature extreme (TN10). It demonstrates that the forthcoming trend pattern in temperature extreme 248 has a strong long-term association with the current state and forthcoming trend pattern. By contrast, the 249 DFA exponent value of the warm indices is higher than DTR, TXX, TX90, while in cold indices, the 250 exponent value of DFA is lower than TNN, TXN and TX10. 
251 In Table 1, the correlation matrix of 10 temperature indices has been exhibited. We assessed the

252 significant associations between the Warm and cold indices $(\mathrm{p}<0.01)$ in this current study. There is a 253 strong significant negative relationship between warm indices and cold indices. In contrast, the warm 254 indices SU, DTR and TXX have a significant positive relationship with cold indices TNN, TXN and 255 TN10, respectively, where their coefficient was $0.395,0.389$ and 0.348 , respectively $(\mathrm{p}<0.01)$. The most 256 significant positive relationship is between TX90 and SU, where the coefficient was $0.756(\mathrm{p}<0.01)$. The 257 warm temperature indices were a significantly positive association with one another. On the other hand, 258 the significant negative relationship has shown in cold temperature indices, while the relationship 259 between TXN and TNN has a significant positive association $(\mathrm{p}<0.05)$. The index selected in this 260 present work can have good indicators of climate warming over Bangladesh.

\section{$261 \quad 3.3$ Spatial patterns of extreme temperature indices}

262 The spatial changes in temperature extremes are exhibited in Figure 4. Nearly -081 to 1.12 days/decade 263 was the change rate of DTR where southern and western parts had an increasing trend, and at the same 264 time, another part faced the decreasing trend while 58\% and $29 \%$ of areas under decreasing and 265 increasing trends, respectively (Figure 4a). In Figure 4b, 65\% of sites remain under the increasing trend 266 of SU, and the change tendency rate was -0.93 to 1.44 days/decade; the southern part demonstrated 267 decreasing tendency. TN10 had a decreasing trend in the south and south eastern regions, where $84 \%$ of 268 areas occupied the decreasing trend (Fig. c). The trend change rate of TN10 was -0.5 to 1.22 269 days/decade in Figure 4c. The trend rate of TX10 was -1.37 to 0.3 days/decade, decreasing trend found 270 in northern and southern parts, and $23 \%$ of areas remain under increasing direction (Figure 4d). The 271 change rate of TN90 was -0.25 to 1.63 days/decade, and the northern and southern parts met the 272 increasing trend where $50 \%$ of areas were under increasing trend (Figure 4e). Figure $4 \mathrm{f}$ exhibits that 273 TX90 had -1.6 to 1.45 days/ decade change rate and 67\% area under increasing and $25 \%$ area under 
274 decreasing rate where western and southern part faced increasing trend and the other part met decreasing 275 trend. The change rate of TNN was -1.50 to 1.51 days/decade, with $69 \%$ of station stayed under

276 increasing tendency in the northern, western and southern regions (Figure 4g). TNX had a -1.14 to 1.50 277 rate of change; $80 \%$ of areas demonstrated a declining trend in the western and southern region (Figure $2784 \mathrm{~h})$. In Figure 4i, the change rate was within -1.44 to 1.15 days/decade for TXN, and the higher 279 decreasing rate was in the southern region; 73\% station was under decreasing trend. The variation rate in 280 TXX varied from -1.41 to 1.03 days/decade, where $56 \%$ of areas show a declining pattern in the 281 southern part of the study area (Figure $4 \mathrm{j}$ ). The trending behaviour of extreme temperature indices varied 282 spatially, further assured by temporal distribution in the earlier part.

\subsection{Factor analysis of temperature extreme indices}

284 Factor analysis was carried out to detect the most influential factor affecting extreme temperature 285 indices. F1, comprising TN90, SU and TNX indices of temperature, the overall variance of temperature 286 data is $40.76 \%$, which denotes the warm night primarily controls the general warming trend of 287 temperature extremes over Bangladesh from 1980 to 2015 (Table 3). Daily temperature range (DTR), 288 SU, and TX90 control F2 calculated $22.40 \%$ of the whole variance, ensuring the rising of DTR is the 289 principal factor that affects changes in yearly temperature. The DTR reflects the association between the 290 minimum and maximum temperatures. About $11.83 \%$ of the total variance accounted for F3, where Min 291 Tmax (TXN) dominates the third factor. For F4, the coldest days (TNN) and warmest days (TXX) are 292 the major dominant factors that represent the overall variance of $9.49 \%$ and $4.88 \%$, indicating the 293 warming climate has occurred daily minimum and maximum temperatures to rise significantly. In most 294 cases, warm and cold extremes have a significant statistical association with the average annual 295 temperature (You et al., 2011).

\subsection{Variation of probability distribution functions of temperature extreme}


297 Due to the variations in temperature extremes, the relative indices were chosen to explore the 298 probability distribution function (PDF) of extreme temperature phenomena (Figure 5) in the previous 299 four decades. The frequency has declined in cold extremes while the frequency has increased in warm 300 indices in a recent decade over Bangladesh, which also is consistent with temporal trend analysis. The 301 cold extremes were moved negatively (Figure 4c, 4e, 4g and 4i) while warm extremes (Figure 4a, 4b, $3024 \mathrm{~d}, 4 \mathrm{f}, 4 \mathrm{~h}$ and $4 \mathrm{j}$ ) positively shifted to their upper trails. The movement of negative and positive of the 303 curve of PDF denotes that frequency is declined of cold extremes and increased in frequency of warm 304 extremes. It is worth mentioning that the variations of the PDF curve are more evident in recent decades 305 than in the past three decades. In warm indices, the highest peak was found in 1990 to 1999 and 2000 to 3062009 for DTR, SU and TXX. The recent two decades were for TNX, and 1980 to 1989 was for TN90, 307 and 1990 to 1999 was for TX90. In cold indices, the maximum peak was found in the decades of 2000 to 3082009 for TN10, TX10 and TXN and 1980 to 1989 was for TNN.

\section{$309 \quad 3.6$ Rate of change analysis using Sen's Slope Estimation}

310 The ordinary non-parametric system improved by (Zaiontz 2020) was employed to account for the 311 slopes present in the rate of trend using the Sen's slope estimators (Fig. 6). The positive mark represents 312 the increasing slope, and the declining slope denotes the negative impact. Figure 6a shows that the 313 lowest negative Sen's slope value was -0.764 , primarily found in the northeastern part, and the highest 314 value was found in the southeastern region. The highest positive Sens value was 8.821 for SU (Figure $3156 b)$, which generally exhibited in the northeastern part, while -3.019 was the lowest negative value for 316 TN10 (Figure 6c) which maximum distributed in the northern region of Bangladesh. In Figure 6d, the 317 lowest negative value was -2.279 for TX10, primarily found in Bangladesh's northeastern and southern 318 parts. The north and northeastern parts of Bangladesh have distributed the highest Sen's slope value 3193.649 for TN90 (Figure 6e). The highest positive value was 5.312 for the TX90 (Figure 6f), which 
mainly occupied southern and northern parts. The lowest value was -0.906 for the TNN (Figure 6g), which was commonly found in the country's southern region. Figure 6h exhibits that the northeastern part met the lowest negative value of TNX, which was -0.089. For TXN (Figure 6i), the lowest negative value was -1.4 , mostly occupying the northern part of Bangladesh. The highest positive value was 0.406 , which was distributed in the southern part of Bangladesh.

\subsection{Mutation Analysis of Extreme Temperatures Indices}

The M-K change point detection analysis was performed for each extreme temperature index, and the change year was selected by combining the sliding t-test technique (Table 4). Table 4 shows that overall Bangladesh, the warm indices (DTR, SU, and TX90) and the cold indices (TNN and TX10) did not change, but the remaining warm (TN90, TNX, TXX) and cold indices (TN10, and TXN) were changed significantly $(\mathrm{p}<0.05)$. The station-wise warm and cold indices were muted. For warm index, in different stations, the points of change happened in the last 20th and the beginning of the 21 st century where stations like Patuakhali, Rangpur for SU, Mymensingh, Patuakhali and Sitakundu for TXX, and Bhola, Jashore, Patuakhali and Mymensingh for TX90 met the change point in the 1980s and later in 2008. In cold indices, their mutation point was also the beginning of the 21st and last of the 20th, where Rangamati and Sitakundo for TNN, Chattogram and Teknaf for TN10 faced the mutation point after 1987 and 2005. The points of mutation of all indexes of temperature extremes passed 0.05 level of test of significance. It can be observed that the mutation point is varied from region to region. In those stations, warm indices such as TXX and TX90 were muted in 1986, 1987 while cold indices including TNN and TN10 were muted in 1988 and 1989. Overall, the mutation points of warm indices were before cold indices and other indices. Similarly, it implied that the warm indices were more sensitive to global climate warming than cold indices.

\section{Discussion}


343 Extreme weather occurrences have drawn attention to the massive dominance of extreme climate 344 changes on life, nature and human production in recent years (Weaver et al. 2014; Li et al., 2013). Due 345 to getting how extreme climate influences the natural environment and society. It is significantly 346 essential to assess climate extremes' spatial and temporal change trend. In this present study, we 347 evaluated the temporal and spatial changes in temperature extremes in Bangladesh in the previous 36 348 years (1980-2015). The results exhibited that the trend of warm indices increased while TXX showed 349 decreasing trend and the cold indices are meeting decreasing trend. This result is consistent with $\mathrm{Li}$ et al. 350 2020, where they explored that the warm indices including WSDI, TR20, SU25, Tx90p and Tn90p are 351 increasing, and the cold indices such as CSDI, ID0, FD0, Tx10p and Tn10p are decreased. Zhou et al. 352 (2020) explored those warm indices in China showed an increasing trend while cold indices exhibit a 353 declining tendency except TXN and TNN, which agrees with the present study. Sun et al. (2015) 354 investigated that cold extremes are significantly declining in China, similar to the current research. The 355 warm occurrences are increased and decreased considerably the cold events stated by Ren et al. (2010), 356 which is in line with the present study. The warm days are increased by 0- 0.3 days/ decade in china (Shi 357 et al. 2018). Jiang et al. (2016) assessed that the cold indices TX10 and TN10 are declined whether the 358 warm indices TX90 and TN90 increase in the Tibetan plateau. Cold extremes and warm extremes 359 exhibited downward and upward trend, respectively, in the assessment of $\mathrm{Yu}$ and Li (2016), which is 360 similar to the current research findings. We have explored the correlation between warm indices and 361 cold indices. Warm and cold indices with each other were investigated. Those warm temperature indices 362 (SU, TNX, and TN90) will be increasing in future than the other warm indices, while cold indices TN10 363 will decline in coming days than other cold indices by using the DFA exponent.

364 The warm and cold extremes were significantly negatively correlated except for the relationship 365 between SU and TNN, DTR and TXN, TXX and TN10. This outcome is consistent with Yu et al. 
(2015). A similar study has also done by You et al. (2013); You et al. (2011), Zhai and Pan, (2003). DTR is increasing in the southern and western part of Bangladesh for the SU, and southern part met the decreasing tendency, south and southeastern part demonstrating the decreasing trend for TN10, TX10 met the decreasing trend in the south and northern part. TN90 show the increasing trend in the north and southern part of Bangladesh, south and western region met increasing trend for TX90. Approximately $69 \%$ of the northern, western and southern parts of Bangladesh met increasing tendency of TNN, -1.14 to 1.50 was the change rate of TNX and different parts of the country were faced decreasing. A rising trend, southern part experiences the decreasing trend for TXN and TXX analyzed by spatial distribution in this current research work. Similar research work is also done by Zhou et al. (2020) where they found that the warm and cold indices are facing increasing and decreasing pattern in different parts of the study area. Li et al. (2020) found that TNN and TXX spatially varied, which agrees with the present study's outcomes. Some studies performed in North-Eastern regions of India are in good agreement with our finding (Jhajharia et al. 2014). Dabral et al. (2016) indicated that minimum temperature is rising in the north-eastern part of India which is quite dissimilar to this finding. Results indicate that the frequency and intensity of warm night is enhancing in the North-Eastern region of India (Jhajharia and Singh 2011; Dabral et al. 2016), similar to our study.

$\mathrm{Yu}$ and $\mathrm{Li}$ (2014) investigated the spatial distribution of temperature indices in line with the current study's findings. The almost same study conducted by Zhao and Chen (2021), You et al. (2011), Nie et al. (2012). The present study assessed the principal factor, which was DTR, and it also influences the variation of annual temperature, and its total variance was $22.40 \%$. This outcome is consistent with $\mathrm{Yu}$ and Li 2014 where they found that SU25 is the principal factor of yearly temperature change. You et al. 2011 also explored similar findings. By using the probability distribution function, it discovered that warm indices are shifted positively. Cold indices are moved negatively, which further indicated that the 
warm indices are following an increasing trend while cold indices are decreasing trend and the density peak was different for each temperature extremes. The variations were most remarkable in the recent decades in this research study. This result is almost similar to Yu and Li (2014). Liu et al. (2021) found that the temperature extremes varied differently in different regions while the significant variations were in recent decades, consistent with the present study. The outcome of Fu and Ding (2021) is in line with the current research.

In this study, we have analyzed the change point of temperature extremes where we found that the change point of warm and cold indices was last of the twentieth and beginning of the twenty-one century. Zhou et al. (2020) investigated that the mutation point for warm indices was beginning in the twenty-first century, which is in good agreement with the present research work. Liu et al. (2021) explored the change point of temperature extremes. By contrast, the daily maximum temperature altered quicker than the daily minimum temperature. The main reason is the probable urbanization impact on the extreme temperature indices (Zhou and Ren, 2011). The urbanization impact may be aggravated by extreme temperature trends associated with daily maximum temperature in Bangladesh. However, the rapid urbanization impacts of extreme temperature indices related to daily minimum temperatures were generally trivial (Duan et al., 2012).

Therefore, the increasing pattern of warm indices and decreasing cold indices have already influenced vegetation succession, soil and farm production over Bangladesh. There will be more intense consequences and uprising extreme weather occurrences and temperature forecasted in the coming days. The achieved outcomes have scientific and practical implications, which assist policy-makers in developing suitable measures to safeguard vegetation change and lessen the detrimental impacts triggered by extreme climatic phenomena. Our study aims to understand extreme climatic phenomena in Bangladesh. Environmental factors such as soil moisture content, potential evapotranspiration, pan 
412 evaporation and land use/land cover changes should be considered in future studies. The extreme 413 temperature influences vegetation dynamics in future based on CMIP6 datasets in Bangladesh deserves 414 further investigation.

\section{5. Conclusion}

416 This paper aims to detect temporal and spatial trends of extreme temperatures in Bangladesh in the past 41737 years (1980-2017) using multi-statistical modeling approaches. The results show that warm 418 temperature indices in Bangladesh were increasing in the last four decades except for the warmest days 419 (TXX), especially before the 2000s, while cold temperature indices showed a decreasing trend after 420 2000. DTR and SU showed an upward trend in the country, indicating that the rising rate of daily 421 maximum temperature in the past four decades was more than that of daily minimum temperature. This 422 confirms that Bangladesh is uninterruptedly developing towards a warmer trend, which is a negative 423 response to global climate warming. Spatially, the change rate of warm indices was the largest in the 424 northwest region and the smallest in the eastern part. Besides, the change speed of DTR at each station 425 was less than that of other indices, whose change tendency rate was the smallest in the central region 426 and the decrease speed was more prominent in the northern part. The outcomes of DFA showed a long427 range association among extreme temperature indices, implying that warm and cold indices will 428 continue their present trend in the upcoming years, except for cold days will not sustain their current 429 trend in the future. By using the probability distribution functions, the variations of the curves are more 430 evident in recent decades than in the past three decades. Based on factor analysis, the warm night 431 primarily controls the general warming trend of temperature extremes over Bangladesh from 1980 to 432 2017. Mutation analysis revealed that the mutation points of the warm index were before cold index and 433 other indices, indicating that warm indices were more sensitive to global climate warming than cold 434 indices. The increase in the warm indices and the decrease in the cold indices have eventually impacted 
agricultural crop production, soil fertility and vegetation dynamics in northwest Bangladesh. Rising temperature and the increase in extreme climatic phenomena forecasted in the future will have a more

437 intense impact on sustainable development. Thus, to confirm the country's sustainable development, 438 governments at all levels should systematically take adequate countermeasures based on climate change 439 characteristics and constantly develop their capacity to cope with extreme climatic phenomena.

440 Acknowledgement

441 The authors extend their appreciation to the Deanship of Scientific Research at King Khalid University 442 for funding this work through Research Group under grant number (R.G.P.2 /194/42). We are grateful to 443 the Department of Disaster Management, Begum Rokeya University, Rangpur for all sort of assistant 444 provided during this study. Furthermore, we would like to thank the Bangladesh Meteorological 445 Department (BMD) for providing required data for this research.

446 Ethical approval

$447 \quad$ Not applicable

448 Consent to Participate

449 Not applicable

450 Consent to Publish

$451 \quad$ Not applicable

452 Data availability

453 Data are available upon request on the corresponding author

454 Author contributions

455 A.R.M.T.I., J.M., and H.M.T.I., B.G., designed, planned, conceptualized, drafted the original manuscript, and 456 H.M.T.I, and Y.R., were involved in statistical analysis, interpretation; H.M.T.I., Y.R., and J.M., contributed 457 instrumental setup, data analysis, validation; Z.H., and S.A.B., contributed to editing the manuscript, literature 458 review, proofreading; B.G., J.M., Z.H., and A.R.M. T.I., were involved in software, mapping, and proofreading 459 during the manuscript drafting stage.

460 Conflict of interest

461 There is no conflict of interest to publish this work.

462 Funding statement 
The authors extend their appreciation to the Deanship of Scientific Research at King Khalid University for funding this work through Research Group under grant number (R.G.P.2 /194/42).

\section{Reference}

1. Abiodun, B.J., Salami, A.T., Matthew, O.J. et al. (2013). Potential impacts of afforestation on climate change and extreme events in Nigeria. Clim Dyn 41,277-293. https://doi.org/10.1007/s00382-012-1523-9

2. Aguilar, E., Peterson, T. C., Obando, P. R., Frutos, R., Retana, J. A., Solera, M., ... \& Mayorga, R. (2005). Changes in precipitation and temperature extremes in Central America and northern South America, 1961-2003. Journal of Geophysical Research: Atmospheres, 110(D23).

3. Alexander, L. V., Zhang, X., Peterson, T. C., Caesar, J., Gleason, B., Klein Tank, A., Haylock, M., Collins, D., Trewin, B. \& Rahimzadeh, F. 2006. Global observed changes in daily climate extremes of temperature and precipitation. Journal of Geophysical Research: Atmospheres, 111.

4. Allen, C. D., Macalady, A. K., Chenchouni, H., Bachelet, D., McDowell, N., Vennetier, M., et al. (2010). A global overview of drought and heat-induced tree mortality reveals emerging climate change risks for forests. Forest ecology and management, 259(4), 660-684.

5. Bandyopadhyay S, Kanji S, Wang L (2012) The impact of rainfall and temperature variation on diarrheal prevalence in Sub-Saharan Africa. Appl Geogr 33:63-72.

6. Benestad, R.E., Haugen, J.E. (2007). On complex extremes: flood hazards and combined high spring-time precipitation and temperature in Norway. Climatic Change 85, 381-406. https://doi.org/10.1007/s10584-007-9263-2

7. Ciais, P., Reichstein, M., Viovy, N., et al. (2005). Europe-wide reduction in primary productivity caused by the heat and drought in 2003. Nature 437 (7058), 529-534.

8. Coumou, D., \& Rahmstorf, S. (2012). A decade of weather extremes. Nature climate change, 2(7), 491-496.

9. Coumou, D., Robinson, A. \& Rahmstorf, S. (2013). Global increase in record-breaking monthlymean temperatures. Climatic Change 118, 771-782. https://doi.org/10.1007/s10584-012-0668-1

10. Dabral PP, Saring T, Jhajharia D (2016) Time series models of monthly rainfall and temperature to detect climate change for Jorhat (Assam), India. Global NEST Journal, 18(3): 494-507. 
11. Donat, M. G., Peterson, T. C., et al. (2014). Changes in extreme temperature and precipitation in the Arab region: long-term trends and variability related to ENSO and NAO. International Journal of Climatology, 34(3), 581-592.

12. Duan, C.; Miu, Q.; Cao, W.; Ma, D. (2012). Effect of Urbanization on Variation Trends of Air Temperatures Based on Mountain Stations. Atmos. Sci. 35, 811-812.

13. Easterling, D. R., Evans, J. L., Groisman, P. Y., Karl, T. R., Kunkel, K. E. \& Ambenje, P. (2000).Observed variability and trends in extreme climate events: a brief review. Bulletin of the American Meteorological Society, 81, 417-426.

14. Eckstein, D., Künzel, V., \& Schäfer, L. (2017). Global climate risk index 2018. Germanwatch, Bonn.

15. Endfield, G. H. (2012). The resilience and adaptive capacity of social-environmental systems in colonial Mexico. Proceedings of the National Academy of Sciences, 109(10), 3676-3681.

16. Finkel, J.M.; Katz, J.I. (2018). Changing world extreme temperature statistics. Int. J. Climatol. $38,2613-2617$.

17. Fu D, Ding Y. (2021). The study of changing characteristics of the winter temperature and extreme cold events in China over the past six decades. Int J Climatol. 41: 2480-2494. https://doi.org/10.1002/joc.6970

18. Gallant, A.J.E.; Karoly, D.J. (2010). A combined climate extremes index for the Australian region. J. Clim., 23, 6153-6165.

19. Gao, M.; Franzke, C.L.E. (2017). Quantile regression-based spatiotemporal analysis of extreme temperature change in China. J. Clim. 30, 9897-9914.

20. García-Cueto, O.R.; Cavazos, M.T.; de Grau, P.; Santillán-Soto, N., (2014) Analysis and Modeling of Extreme Temperatures in Several Cities in Northwestern Mexico under Climate Change Conditions. Theor. Appl. Climatol., 116, 211-225.

21. Guo, E.; Zhang, J.;Wang, Y.; Quan, L.; Zhang, R.; Zhang, F.; Zhou, M. (2019) Spatiotemporal Variations of Extreme Climate Events in Northeast China during 1960-2014. Ecol. Indic, 96, $669-683$.

22. Ghose, B., Islam, A.R.M.T., Islam, H.M.T., et al. (2021). Rain-fed rice yield fluctuation to climatic anomalies in Bangladesh. Int. J. Plant Prod. https://doi.org/10.1007/s42106-021-00131-X 
23. Gleixner, S.; Demissie, T.; Diro, G.T. (2020). Did ERA5 Improve Temperature and Precipitation Reanalysis over East Africa? Atmosphere (Basel) 11, 996.

24. Guan, Y.; Zhang, X.; Zheng, F.; Wang, B. (2015). Trends and variability of daily temperature extremes during 1960-2012 in the Yangtze River Basin, China. Glob. Planet. Chang. 124, 7994.

25. Hans, A. (1986). A homogeneity test applied to precipitation data. Int. J. Climatol. 6 (6), 661675.

26. Hasan, A. B. M. S. U., \& Rahman, M. Z. (2013). Change in temperature over Bangladesh associated with degrees of global warming. Asian Journal of Applied Science and Engineering, 2(2), 62-75.

27. Hidalgo-Muñoz, J. M., Argüeso, D., Gámiz-Fortis, S. R., Esteban-Parra, M. J., \& Castro-Díez, Y. (2011). Trends of extreme precipitation and associated synoptic patterns over the southern Iberian Peninsula. Journal of Hydrology, 409(1-2), 497-511.

28. Islam, A.R.M.T., Islam, H.M.T., Shahid, S., Khatun, M.K., Ali, M.M., Rahman, M.S., Ibrahim, S.M. and Almoajel, A.M. (2021). Spatiotemporal nexus between vegetation change and extreme climatic indices and their possible causes of change. Journal of Environmental Management, 289, 112505.

29. Islam, A.R.M.T., Rahman, M.S., Khatun, R., Hu, Z., (2020). Spatiotemporal trends in the frequency of daily rainfall in Bangladesh during 1975-2017. Theor. Appl. Climatol. 141, 869887

30. Islam, A.R.M.T., Shen, S., Yang, S.B., Hu, Z., Chu, R. (2019). Assessing recent impacts of climate change on design water requirement of Boro rice season in Bangladesh. Theor. Appl. Climatol. 138, 97-113.

31. Jhajharia D, Dinpashoh Y, Kahya E, Choudhary RR, Singh VP (2014) Trends in temperature over Godavari river watershed in southern peninsular India. Inter J Climatology 34: 1369-1384.

32. Jhajharia D, Singh VP (2011) Trends in temperature, diurnal temperature range and sunshine duration in Northeast India. International Journal of Climatology, 31(9): 1353-1367.

33. Jerin, J.N., Islam, H.M.T., Islam, A.R.M.T. et al. (2021). Spatiotemporal trends in reference evapotranspiration and its driving factors in Bangladesh. Theor Appl Climatol 144, 793-808. https://doi.org/10.1007/s00704-021-03566-4 
34. Jiang, C.; Mu, X.;Wang, F.; Zhao, G. (2016). Analysis of extreme temperature events in the Qingling Mountains and surrounding area during 1960-2012. Quat. Int. 392, 155-167.

35. Jones, P. D., Osborn, T. J., Briffa, K. R., Folland, C. K., Horton, E. B., Alexander, L. V., ... \& Rayner, N. A. (2001). Adjusting for sampling density in grid box land and ocean surface temperature time series. Journal of Geophysical Research: Atmospheres, 106(D4), 3371-3380.

36. Katz, R.W.; Brown, B.G. (1992). Extreme events in a changing climate: Variability is more important than averages. Clim. Chang. 21, 289-302.

37. Khan, M.J.U., Islam, A.S, Das, M.K., Mohammed, K., Bala, S.K., Islam, G.T. 2019. Observed trends in climate extremes over Bangladesh from 1981 to 2010. Clim Res 77(1):45-61

38. Li, B.; Chen, Y.; Shi, X.; Chen, Z.; Li, W. (2013). Temperature and precipitation changes in di_erent environments in the arid region of northwest China. Theor. Appl. Climatol. 112, 589596

39. Li, C., Du, D., Leal Filho, W., Wang, J., Bao, G., Ye, M., Ayal, D.Y., Shan, Y., Bao, Y. and Hu, R. (2020). Assessing the implications of temperature extremes during the period 1959-2014 on the Inner Mongolia Plateau to sustainable development. DIE ERDE-Journal of the Geographical Society of Berlin, 151(4), 239-257.

40. Li, Z., \& Zhang, Y. K. (2007). Quantifying fractal dynamics of groundwater systems with detrended fluctuation analysis. Journal of hydrology, 336(1-2), 139-146.

41. Liu, Y. R., Li, Y. P., Yang, X., Huang, G. H., \& Li, Y. F. (2021). Development of an integrated multivariate trend-frequency analysis method: Spatial-temporal characteristics of climate extremes under global warming for Central Asia. Environmental Research, 195, 110859.

42. Mahmud, K., Saha, S., Ahmad, T., Satu, U.S. 2018. Historical trends and variability of temperature extremes in two climate vulnerable regions of Bangladesh. J Bangladesh Agric Univ 16:283-292.

43. Mearns, L. O., Katz, R. W., \& Schneider, S. H. (1984). Extreme high-temperature events: changes in their probabilities with changes in mean temperature. Journal of Applied Meteorology and Climatology, 23(12), 1601-1613.

44. Moberg, A., \& Jones, P. D. (2005). Trends in indices for extremes in daily temperature and precipitation in central and western Europe, 1901-99. International Journal of Climatology: A Journal of the Royal Meteorological Society, 25(9), 1149-1171. 
45. Mu, X. M., Zhang, L., McVicar, T. R., Chille, B. and Gau, P. (2007). Analysis of the impact of conservation measures on stream flow regime in catchments of the Loess Plateau, China. Hydrol. Processes, 21(16): 2124-2134.

46. Nie, C., Li, H., Yang, L., Ye, B., Dai, E., Wu, S., Liu, Y. and Liao, Y. (2012). Spatial and temporal changes in extreme temperature and extreme precipitation in Guangxi. Quaternary International, 263, pp.162-171.

47. Omondi, P. A. O., Awange, J. L., Forootan, E., Ogallo, L. A., Barakiza, R., Girmaw, G. B., ... \& Komutunga, E. (2014). Changes in temperature and precipitation extremes over the Greater Horn of Africa region from 1961 to 2010. International Journal of Climatology, 34(4), 1262-1277.

48. Panda, D.K.; Mishra, A.; Kumar, A.; Mandal, K.G.; Thakur, A.K.; Srivastava, R.C. (2014). Spatiotemporal patterns in the mean and extreme temperature indices of India, 1971-2005. Int. J. Climatol. 34, 3585-3603.

49. Peng, C.K., Buldyrev, S.V., Havlin, S., Simons, M., Stanley, H.E., Goldberger, A.L. (1994). Mosaic organization of DNA nucleotides. Phys. Rev. E 49 (2), 1685-1689.

50. Pettitt, A. N. (1979). A non-parametric approach to the change-point problem. Journal of the Royal Statistical Society: Series C (Applied Statistics), 28(2), 126-135.

51. Piccarreta, M., Lazzari, M., \& Pasini, A. (2015). Trends in daily temperature extremes over the Basilicata region (southern Italy) from 1951 to 2010 in a Mediterranean climatic context. International Journal of Climatology, 35(8), 1964-1975.

52. Praveen, B., Talukdar, S., Shahfahad, Mahato, S., Mondal, J., Sharma, P., Islam, A.R.M.T., Rahman, A. (2020). Analyzing trend and forecasting of rainfall changes in India using nonparametrical and machine learning approaches. Scientific Reports, 10(1). doi:10.1038/s41598020-67228-7

53. Rahman, M.S., Islam, A.R.M.T. (2019). Are precipitation concentration and intensity changing in Bangladesh overtimes? Analysis of the possible causes of changes in precipitation systems. Sci. Total Environ. 690, 370-387. https://doi.org/10.1016/j.scitotenv.2019.06.529

54. Rahman MA, Yunsheng L, Sultana N, Ongoma V (2019) Analysis of reference evapotranspiration (ET0) trends under climate change in Bangladesh using observed and CMIP5 data sets. Meteorog Atmos Phys 131:639-655. https://doi.org/10.1007/s00703-018-0596-3

55. Rammig, A., \& Mahecha, M. D. (2015). Ecosystem responses to climate extremes. Nature, 527(7578), 315-316. 
56. Ren, G.Y.; Feng, G.L.; Yan, Z.W. (2010). Progresses in observation studies of climate extremes and changes in mainland China. Clim. Environ. Res. 15, 337-353.

57. Sacks, W. J., \& Kucharik, C. J. (2011). Crop management and phenology trends in the US Corn Belt: Impacts on yields, evapotranspiration and energy balance. Agricultural and Forest Meteorology, 151(7), 882-894.

58. Salam, R., \& Islam, A. R. M. T. (2020). Potential of RT, Bagging and RS ensemble learning algorithms for reference evapotranspiration prediction using climatic data-limited humid region in Bangladesh. Journal of Hydrology, 590, 125241.

59. Salam R, Islam ARMT, Pham QB, Dehghani M, Al Ansari N, Linh NTT (2020) The optimal alternative for quantifying reference evapotranspiration in climatic sub-regions of Bangladesh, Scientific Reports, Sci Rep 10 (1), 20171, DOI: 10.1038/s41598-020-77183-y

60. Sarker, M. A. R., Alam, K., \& Gow, J. (2012). Exploring the relationship between climate change and rice yield in Bangladesh: An analysis of time series data. Agricultural Systems, 112, 11-16.

61. Sharma, P.J.; Loliyana, V.D.; Resmi, S.R.; Timbadiya, P.V.; Patel, P.L. (2018) Spatiotemporal Trends in Extreme Rainfall and Temperature Indices over Upper Tapi Basin, India. Theor. Appl. Climatol., 134, 1329-1354.

62. Schmidli, J., and Frei C. (2005). Trends of heavy precipitation and wet anddry spells in Switzerland during the 20th century,Int. J. Climatol.,25,753-771.

63. Sen, P.K. (1968). Estimates of the regression coefficient based on Kendall's tau. J. Am. Stat. Assoc. 63, 1379-1389.

64. Shahid, S., Wang, X.-J., Harun, S. B., Shamsudin, S. B., Ismail, T., and Minhans, A. 2016. Climate variability and changes in the major cities of Bangladesh: observations, possible impacts and adaptation. Regional Environmental Change, 16(2), 459-471.

65. Sheikh, M., Manzoor, N., Ashraf, J., Adnan, M., Collins, D., Hameed, S., Manton, M., Ahmed, A., Baidya, S. \& Borgaonkar, H., 2015. Trends in extreme daily rainfall and temperature indices over South Asia. Int J Climatol. 35, 1625-1637.

66. Shi, J.; Cui, L.; Ma, Y.; Du, H.W. (2018). Trends in temperature extremes and their association with circulation patterns in China during 1961-2015. Atmos. Res. 2122, 59-72.

67. Sikder, R., \& Xiaoying, J. (2014). Climate change impact and agriculture of Bangladesh. Journal of Environment and Earth Science, 4(1), 35-40. 
68. Smith, M. D. (2011). The ecological role of climate extremes: current understanding and future prospects. Journal of Ecology, 99(3), 651-655.

69. Sun, Q.; Miao, C.; Duan, Q. (2015). A projected changes in temperature and precipitation in ten river Basins over China in 21st century. Int. J. Climatol. 35, 1125-1141.

70. Sun, Y., et al. (2014). Rapid increase in the risk of extreme summer heat in Eastern China, Nat. Clim. Change, 4, 1082- 1085.

71. Tank, A. K. et al. (2006). "Changes in daily temperature and precipitation extremes in central and south Asia." Journal of Geophysical Research 111.

72. Ullah, S., You, Q., Ullah, W., Ali, A., Xie, W., \& Xie, X. (2019). Observed changes in temperature extremes over China-Pakistan Economic Corridor during 1980-2016. International Journal of Climatology, 39(3), 1457-1475.

73. Weaver, S.J.; Kumar, A.; Chen, M. (2014). Recent increases in extreme temperature occurrence over land. Geophys. Res. Lett. 41, 4669-4675

74. You, Q. L., Ren, G. Y., Zhang, Y. Q., Ren, Y. Y., Sun, X. B., Zhan, Y. J., ... \& Krishnan, R. (2017). An overview of studies of observed climate change in the Hindu Kush Himalayan (HKH) region. Advances in Climate Change Research, 8(3), 141-147.

75. You, Q.L., Kang, S.C., Aguilar, E., Pepin, N., Flügel, W.A., Yan, Y.P., Xu, Y.W., Zhang, Y.J., Huang, J., (2011). Changes in daily climate extremes in China and its connection to the large scale atmospheric circulation during 1961-2003. Climate Dynamics 36, 2399-2417.

76. You, Q.L., Ren, G.Y., Fraedrich, K., Kang, S.C., Ren, Y.Y., Wang, P.L., (2013). Winter temperature extremes in China and their possible causes. International Journal of Climatology 33 (6), 1444-1455.

77. Yu, E., Sun, J., Chen, H., \& Xiang, W. (2015). Evaluation of a high-resolution historical simulation over China: Climatology and extremes. Climate Dynamics, 45(7), 2013-2031.

78. Yu, Z. and Li, X. (2014). Recent trends in daily temperature extremes over northeastern China (1960-2011). Quaternary International, 380, pp.35-48.

79. Yu, Z.; Li, X. (2016). Recent trends in daily temperature extremes over northeastern China (1960-2011). Quat. Int. 380-381, 35-48

80. Zaiontz, C. (2020). Mann-Kendall test, real statistics using excel. Proudly powered by WordPress. Real Statistics Using Excel: (c) 2012-2019. 
673 81. Zhai, P., Pan, X.H. (2003). Trends in temperature extremes during 1951-1999 in China. Geophysical Research Letters 30, 1913. http://dx.doi.org/10.1029/ 2003GL018004

82. Zhang, X., Alexander, L., Hegerl, G. C., Jones, P., Tank, A. K., Peterson, T. C., ... \& Zwiers, F. W. (2011). Indices for monitoring changes in extremes based on daily temperature and precipitation data. Wiley Interdisciplinary Reviews: Climate Change, 2(6), 851-870.

83. Zhao, N., \& Chen, M. (2021). A Comprehensive Study of Spatiotemporal Variations in Temperature Extremes across China during 1960-2018. Sustainability, 13(7), 3807.

84. Zhou, J.J.; Huang, J.M.; Zhao, X.; Li, L.; Shi, W.; Wang, L.Y.; Wei, W.; Liu, C.F.; Zhu, G.F.; Yang, X.M. (2020). Changes of extreme temperature and its influencing factors in Shiyang river basin, northwest China. Atmosphere 11, 1171.

85. Zhou, Y.; Ren, G. (2011). Change in extreme temperature event frequency over mainland China, 1961-2008. Clim. Res. 50, 125-139. 
Figures

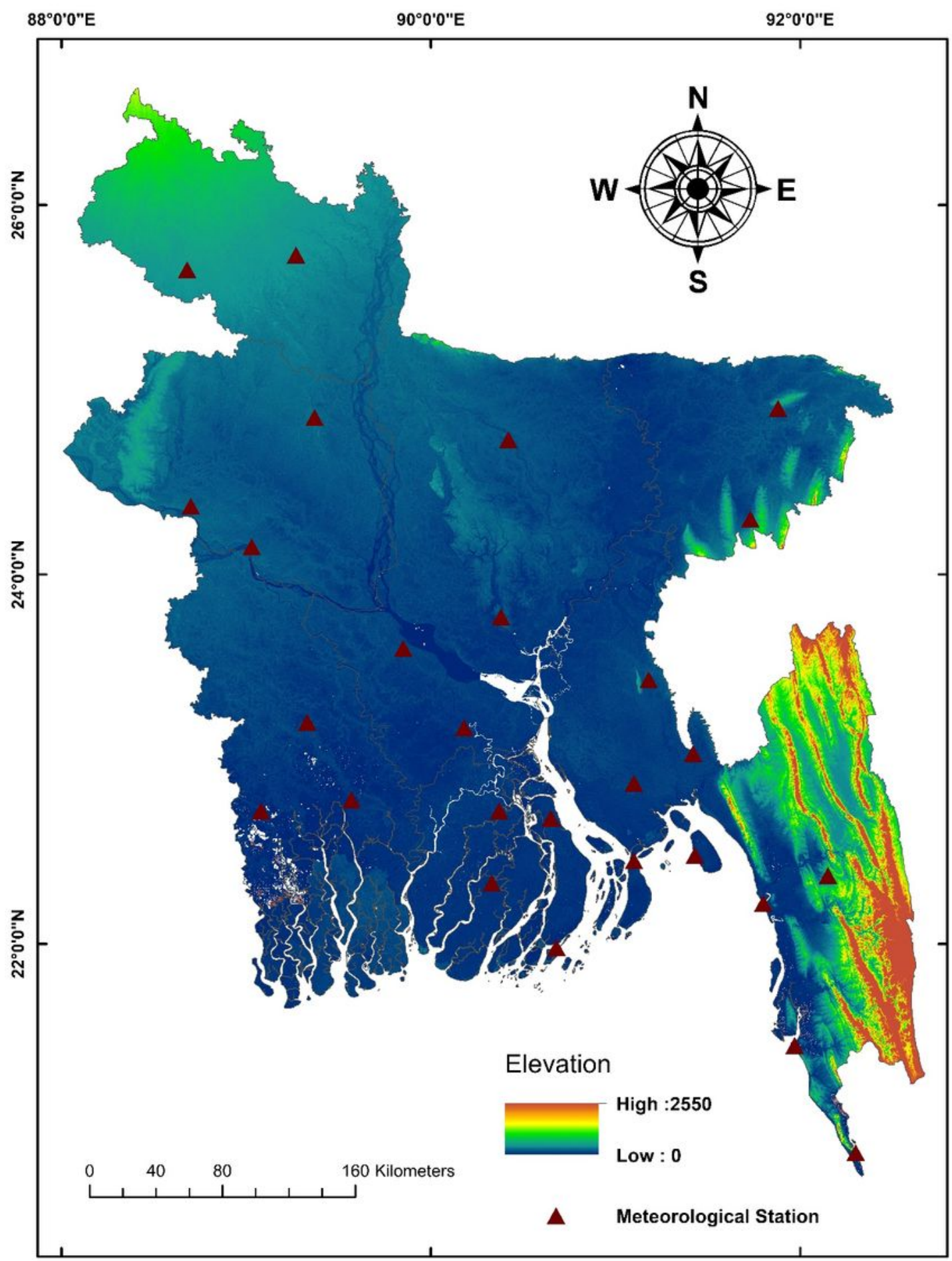

Figure 1

Geographical location of the study area showing meteorological sites 

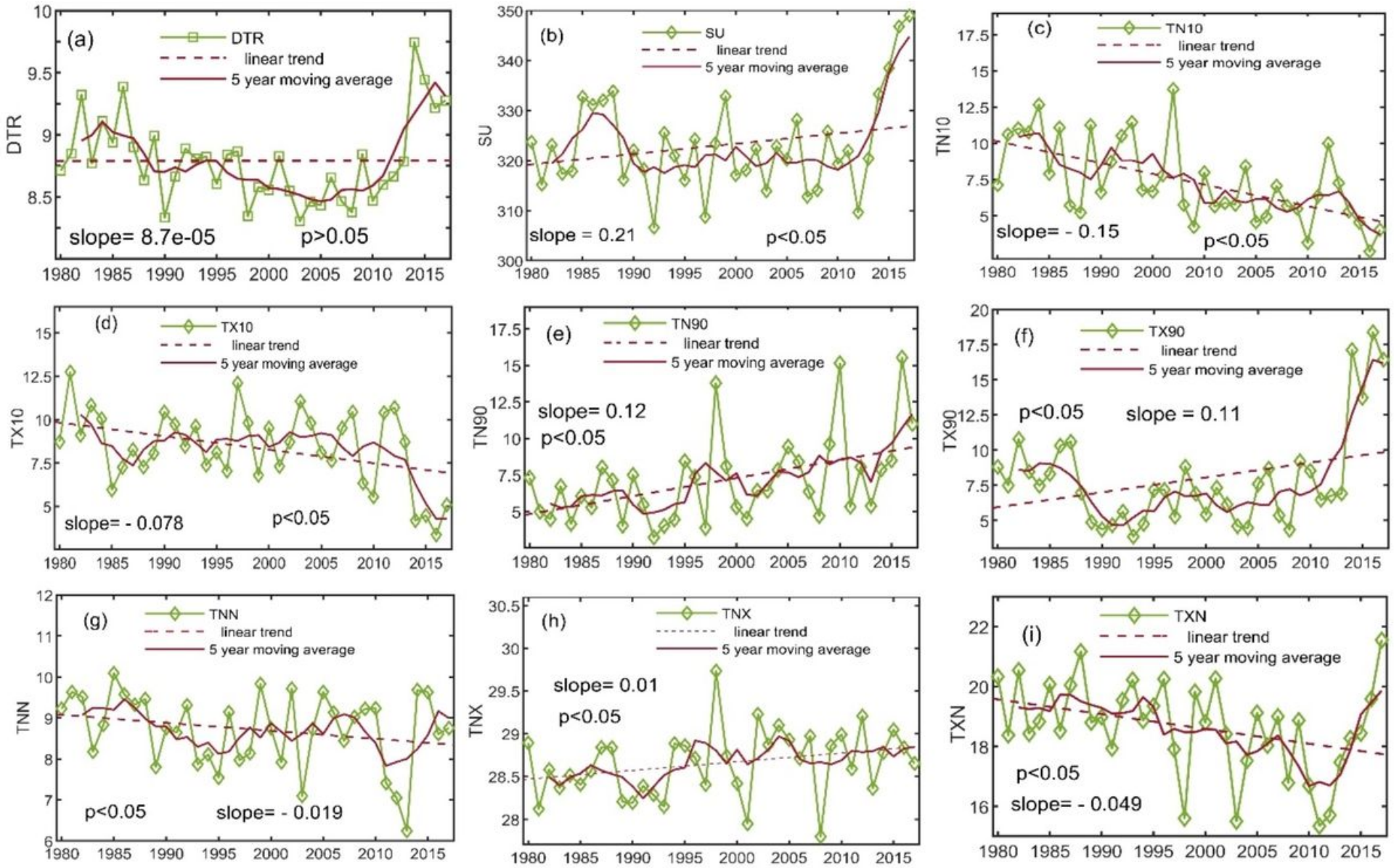

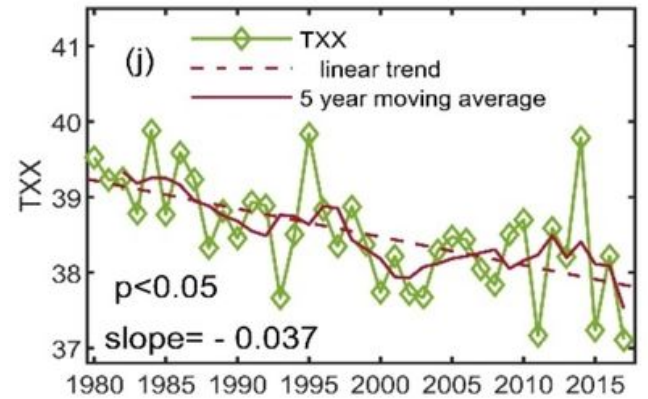

\section{Figure 2}

Linear regression trends for 10 extreme temperature indices during 1980-2017 over Bangladesh 

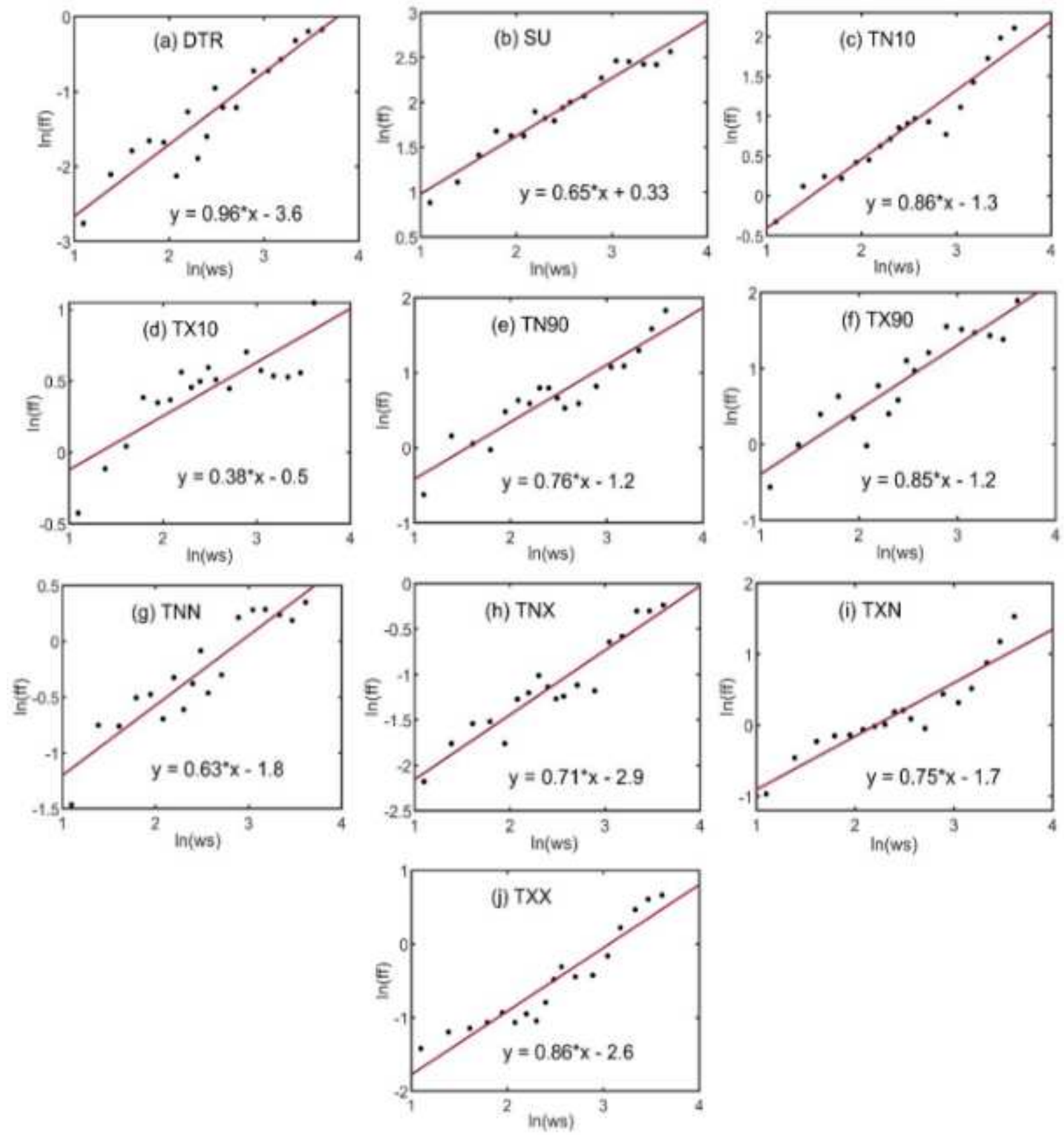

Figure 3

DFA long-term relationships of extreme temperature indices in the forthcoming period across Bangladesh 

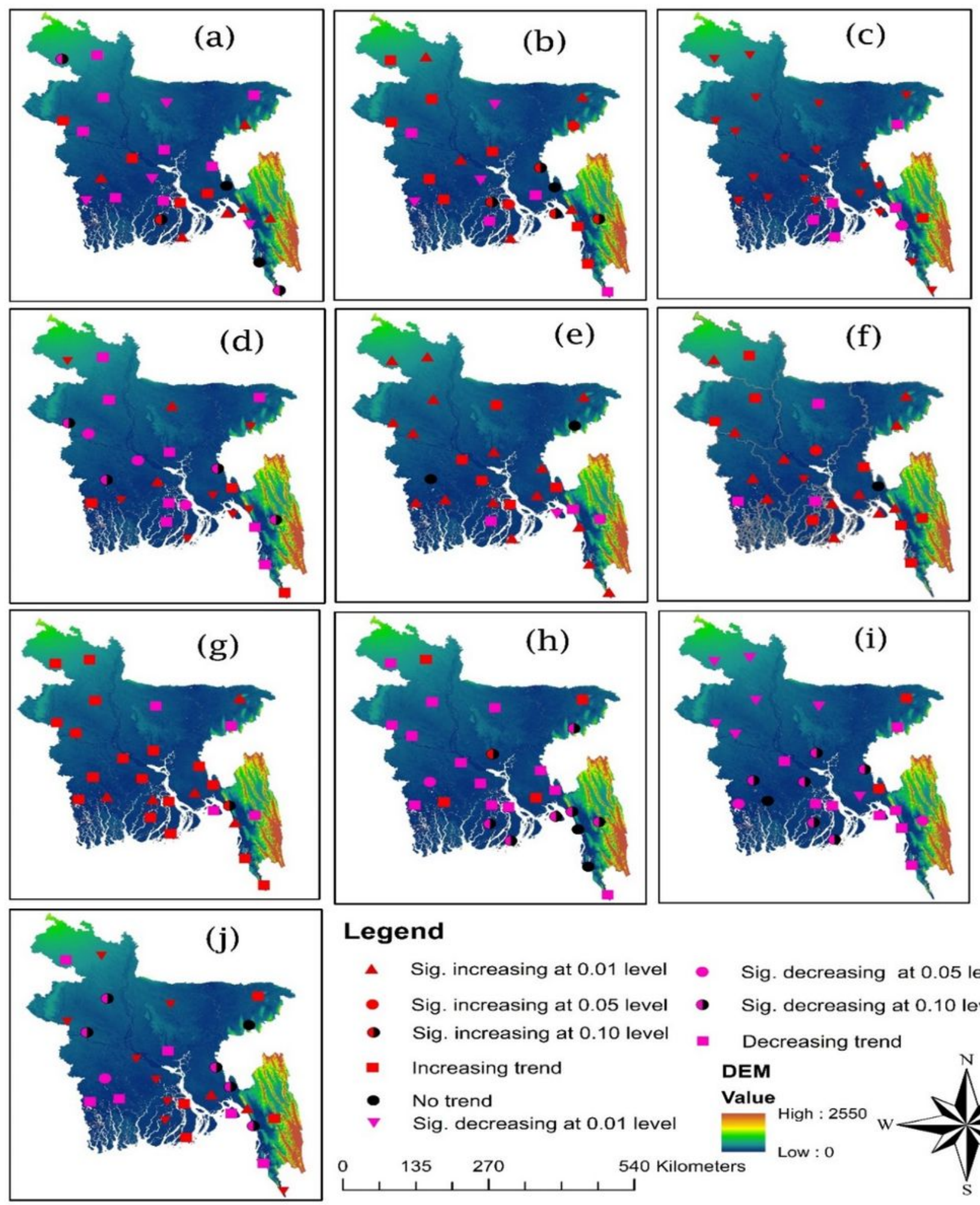

\section{Legend}

- Sig. increasing at 0.01 level

- Sig. increasing at 0.05 level

- Sig. increasing at 0.10 level

- Sig. decreasing at 0.05 level

- Increasing trend

- Sig. decreasing at 0.10 level

- No trend

v Sig. decreasing at 0.01 level

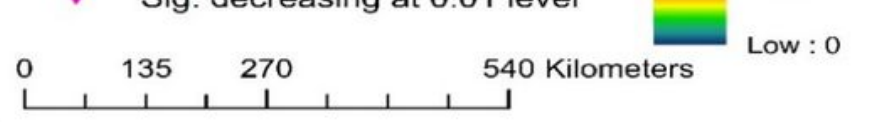

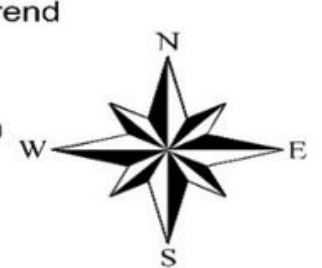

\section{Figure 4}

Spatial distribution patterns of decadal trends in 10 temperature indices over Bangladesh during 1980 to 2017. 

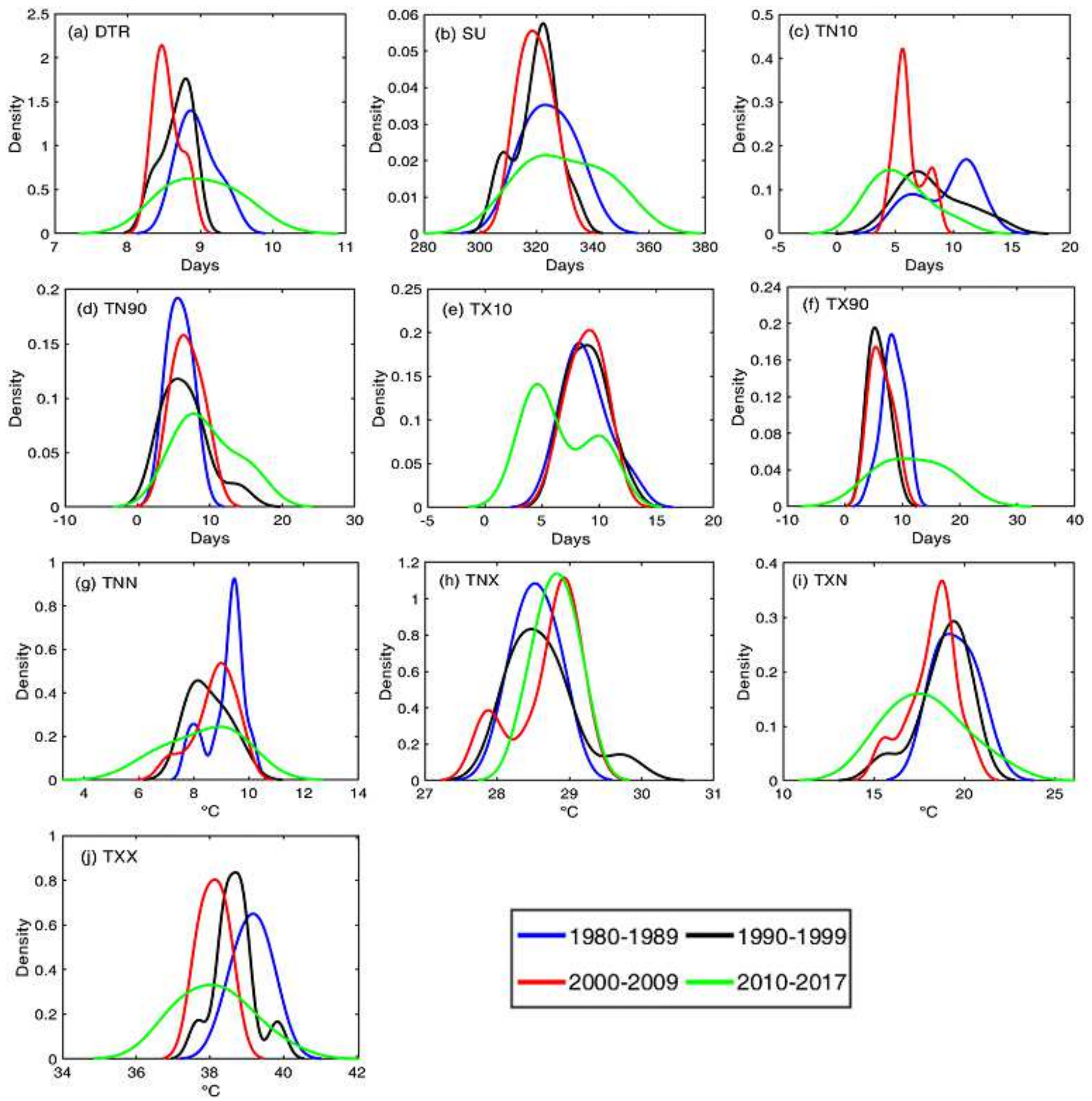

Figure 5

The probability distribution function (PDF) of extreme temperature indices in the last four decades in Bangladesh 

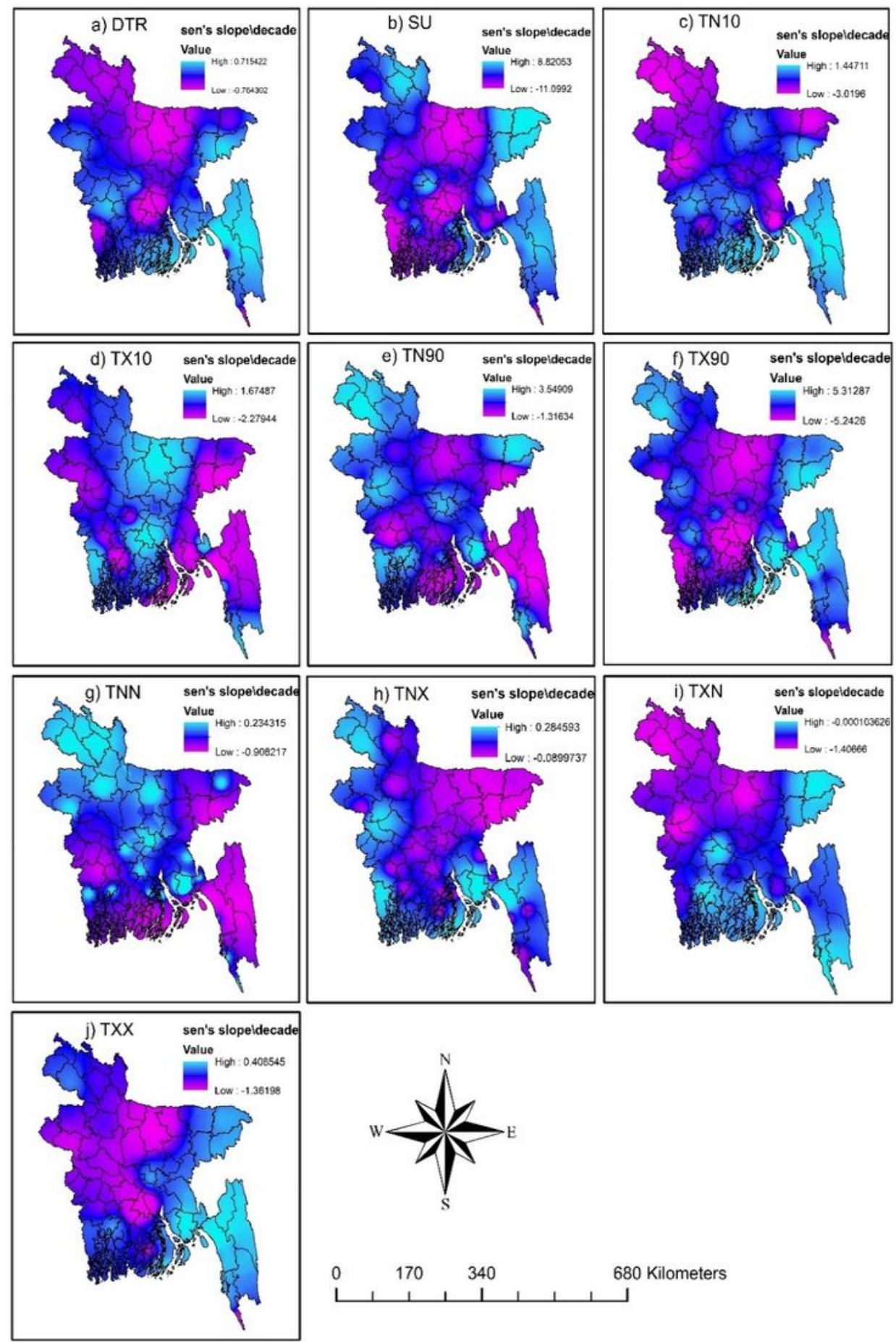

\section{Figure 6}

The rate of trend pattern of extreme temperature indices from 1980-2017 in Bangladesh 